Franziska Anna Zaugg

Rekrutierungen für die Waffen-SS in Südosteuropa 

Franziska Anna Zaugg

\section{Rekrutierungen für \\ die Waffen-SS in \\ Südosteuropa}

Ideen, Ideale und Realitäten einer Vielvölkerarmee

\section{DE GRUYTER \\ OLDENBOURG}


Die Open-Access-Version sowie die Druckvorstufe dieser Publikation wurden vom Schweizerischen Nationalfonds zur Förderung der wissenschaftlichen Forschung unterstützt.

Schweizerischer

Nationalfonds

ISBN 978-3-11-073542-0

e-ISBN (PDF) 978-3-11-073077-7

e-ISBN (EPUB) 978-3-11-073085-2

DOI https://doi.org/10.1515/9783110730777

\section{(cc) BY}

Dieses Werk ist lizenziert unter einer Creative Commons Namensnennung 4.0 International

Lizenz. Weitere Informationen finden Sie unter https://creativecommons.org/licenses/by/4.0/.

\section{Library of Congress Control Number: 2021940635}

\section{Bibliografische Information der Deutschen Nationalbibliothek}

Die Deutsche Nationalbibliothek verzeichnet diese Publikation in der Deutschen Nationalbibliografie; detaillierte bibliografische Daten sind im Internet über http://dnb.dnb.de abrufbar.

(C) 2021 Franziska Anna Zaugg, publiziert von Walter de Gruyter GmbH, Berlin/Boston

Dieses Buch ist als Open-Access-Publikation verfügbar über http://www.degruyter.com.

Coverabbildung: Rekrutierungen in Mitrovica, ECPAD, LFT SO F2684 L03.

Satz: Integra Software Services Pvt. Ltd.

Druck und Bindung: CPI books $\mathrm{GmbH}$, Leck

www.degruyter.com 
„Der Krieg hatte für dich immer zwei Seiten. Da waren die Auszeichnungen, auf die du mitunter stolz warst. Da war aber auch das Bewusstsein, dass alles ein großer, nutzloser, grauenvoller Irrtum war, der dir wertvolle Jahre deiner Jugendzeit gestohlen hatte.“1

1 Aus dem Nachruf Hans Tappeiners an seinen Vater Josef Tappeiner, Neue Latscher Zeitung, November 2010, zitiert nach: Thomas Casagrande, Südtiroler in der Waffen-SS: Vorbildliche Haltung, fanatische Überzeugung, Bozen: Edition Raetia 2015,S. 48. 

Gewidmet allen Verstorbenen, Vermissten, Vergewaltigten, Vertriebenen und all jenen, welche von ihren Erinnerungen ein Leben lang verfolgt wurden. 
